\title{
Floceulation of Influenza Virus by Specific Anti-neuraminidase Antibody
}

\author{
By \\ A. P. Kendal and C. R. Madeley \\ Department of Bacteriology, University College Hospital Medical School, London; \\ Department of Medical Microbiology, St. Thomas' Hospital Medical School, London, \\ England \\ With 2 Figures
}

Received November 11, 1969

Summary

1. Flocculation of purified preparations of influenza virus has been demonstrated to occur in the presence of low dilutions of specific anti-neuraminidase sera. High dilutions of the sera caused microscopic aggregation of virions. It is suggested that the effects of anti-neuraminidase antibody on the replication of influenza virus observed in vitro could be caused by antibody binding virions to infected cells, rather than by inhibition of neuraminidase enzymic activity.

2. On examination in the electron microscope of virus floccules obtained with specific anti-neuraminidase sera, surface spikes were clearly seen on the virions. However, when influenza virus was similarly flocculated by serum containing antibodies that inhibited both haemagglutination and neuraminidase activities, the ends of the spikes were almost all completely obscured.

3. Measurement of the Michaelis constant $(\mathrm{Km})$ of $\mathrm{X}-7$ (F 1$)$ neuraminidase shows that the enzyme active site is related to that of $\mathrm{A}_{2} /$ Singapore/57 neuraminidase.

\section{Introduction}

The presence of an enzymic component in the influenza viruses has been recognised for many years, but it is only more recently that the antigenic nature of this enzyme, neuraminidase (E.C.3.2.1.18), has become apparent (RAFELSoN, ScHNETR and WILson, 1963; ADA, LIND and LAVER, 1963). This property of neuraminidase has since been studied to great advantage, and evidence has been obtained by use of recombinant virus strains to show that the antigenic sites on the viral surface which are associated with haemagglutinating and neuraminidase activities are coded by separate parts of the viral genome (KuBourne and Schulmai, 1965; Laver and Kubourne, 1966; Kilbourne et al., 1967; Webster and Laver, 1967; Kilbourne, 1968; Webster, Laver and KILbourne, 1968). Kinetic studies of the chemical inactivation of influenza viruses lead to the 
same conclusion (Scholtissex and Rott, 1964; Scholtissek, Becht and DrzeNIEK, 1967), and the current view is generally held that neuraminidase and haemagglutinating activities are the properties of different viral-specified proteins.

Thus, investigations of the function of neuraminidase in influenza virus infections have often adopted the use of specific anti-neuraminidase antibody to selectively inhibit the activity of this viral component (SETo and RoTr, 1966; Jahiel and Kilbourne, 1966; Seto, Okuda and Hokama, 1967; Webster and Laver, 1967; Seto and Chang, 1969). In the present report, we have examined and commented on a complementary property of anti-neuraminidase antibody, the ability to aggregate influenza virions.

\section{Methods \\ 2.1. Propagation of Virus}

An inhibitor-sensitive variant of the virus strain $A_{2} /$ Singapore/1/57 was grown in the allantoic cavity of 10-11 day old embryonated hens' eggs, as previously described (Kendax et al., 1968). Seed of the recombinant virus strain X-7 (F1) was kindly provided by Dr. G. Schild, of the Medical Research Council Laboratories, Mill Hill, England, and then grown as for $\mathrm{A}_{2} /$ Singapore/1/57. Purified virus was obtained from infected allantoic fluid by one cycle of differential centrifugation followed by rate zonal density gradient centrifugation (KENDAL et al., 1968).

\subsection{Determination of Haemagglutination and Haemagglutination Inhibition}

This was carried out as described by BIDDLE and SHonTRIDGe (1967), except that all volumes were adjusted for use in microtrays. Virus samples for the haemagglutination inhibition test consisted of infected allantoic fluids diluted in $0.15 \mathrm{M}$ saline to contain 16 haemagglutinating units $(\mathrm{HAU}) / \mathrm{ml} .0 .025 \mathrm{ml}$ aliquots were added to equal volumes of serum dilutions and stood at room temperature for 15 minutes before adding fowl red cells. Rabbit sera were treated with periodate before use (LENNETTE and SCHмIDT, 1969), and inhibition titres (HIT) were expressed as the serum dilution causing $50 \%$ inhibition of haemagglutination.

\subsection{Measurement of Neuraminidase Inhibition}

This was performed using the automated procedure described previously for human influenza virus strains, using serum glycoprotein as the enzyme substrate (KENDAL and Madetex, 1969). Titres (NIT) are expressed as the reciprocal of the serum dilution causing $50 \%$ inhibition of observed neuraminidase activity.

\subsection{Flocculation of Virus}

This was performed essentially as described by BELYAVIN (1955). To serial two-fold dilutions of serum $(0.2-0.3 \mathrm{ml})$ in Dreyer agglutination tubes were added equal volumes of purified virus suspensions, containing $500-\mathrm{I}, 000 \mathrm{HAU} / \mathrm{ml}$. The tubes were half-immersed in a $37^{\circ} \mathrm{C}$ water-bath for about 17 hours and the floceulation titre (FT) of each serum was determined as the highest serum dilution giving visible virus floccules at the base of the tubes, as observed with the naked eye using indirect illumination and a dark background.

\subsection{Isolation of Neuraminidase}

Neuraminidase was isolated from purified concentrates of influenza virus by incubation with the bacterial protease nagarse (subtilisin $\mathrm{BPN}^{1}$ ). This treatment digests more than $99 \%$ of the viral haemagglutinin to peptides, releases active neuraminidase, and produces degraded virus particles of reduced buoyant density and sedimentation coefficient, but still containing the bulk of viral nucleic acid (BIDDLE, 1968; Kendal et al., 1968; Kendal, Apostolov and Belyavin, 1969). The degraded 
virus particles were removed by centrifugation through $12-60 \%(\mathrm{w} / \mathrm{v})$ sucrose gradients $(100,000 \times g$ for 90 minutes) and the neuraminidase in solution was recovered in the upper fractions of these gradients. Neuraminidase was then separated from protease and slowly sedimenting viral degradation products by rate zonal centrifugation (ca. $70,000 \times g$ for 17 hours) through further $12-60 \%(\mathrm{w} / \mathrm{v})$ sucrose density gradients. The fractions from these gradients containing the peak of neuraminidase activity were pooled and dialysed against $0.15 \mathrm{M} \mathrm{NaCl}$. This procedure has been described in full previously (KENDAL et al., 1968).

\subsection{Production of Antisera}

Anti-neuraminidase. Two preparations of neuraminidase were isolated from influenza virus $\mathrm{A}_{2} /$ Singapore/57, as described above. These preparations N.1. and N.2., obtained from a nominal 400,000 and 10,000 HAU of virus, respectively, were inoculated into an adult rabbit, and sera were obtained, according to the schedule shown in Table 1.

Anti-whole virus. A rabbit was given two intravenous inoculations with preparations of purified influenza virus at an interval of 3 weeks, and bled 5 days after the second inoculation.

\subsection{Determination of Michaelis Constant of Neuraminidase}

This was performed by the automated procedure previously described, using sialo-lactose substrate (Kendal and MADELEY, 1969).

\subsection{Electron Microscopy of Virus Flocculation}

All floceules were recovered for electron microscopy directly from the agglutination tubes, without centrifugation. For examination by negative staining, the samples were diluted 2-4 fold in distilled water, mixed with an equal volume of $3 \%$ phospho. tungstic acid, $\mathrm{pH}$ 6.0, and a drop was applied to carbon-formwar coated grids. Micrographs were taken in a Philips EM 200, using double condenser illumination and an instrumental magnification of 62,000 .

\section{Results \\ 3.1. Inhibition of Viral Haemagglutinating and Neuraminidase Activities by Antisera}

These tests, performed as described in methods, were carried out against both $A_{2} /$ Singapore/57 virus, and the recombinant virus strain X-7 (F 1). As shown in Table 2, sera prepared against antigens of the Asian parent produced no detectable inhibition of haemagglutination by X-7 (F 1) virus, although high neuraminidase inhibition could be demonstrated. Serum prepared against isolated neuraminidase from $\mathrm{A}_{2} /$ Singapore/57 virus had high neuraminidase inhibitory activity, and a significant level of haemagglutination inhibition was also produced against the homologous virus but not against X-7 (F1). Normal rabbit serum produced very low levels of inhibition in all cases. Horse serum had no significant antineuraminidase activity against the Asian virus enzyme (NIT $<15$ ), although the haemagglutinin of this sensitive variant of $A_{2} /$ Singapore $/ 57$ was strongly inhibited $(\mathrm{HIT}=1,000)$.

\subsection{Kinetic Characteristics of X-7 (Fl) Virus Neuraminidase}

The immunological results described above confirmed other similar evidence that the neuraminidase, but not the 'haemagglutinin', of the recombinant virus $\mathrm{X}-7(\mathrm{Fl})$ is derived from the parent virus $\mathrm{A}_{2} /$ Singapore/57 (KurouRnE et al., 1967; Webster et al., 1968). However, we have previously suggested that the 
antigenic sites and active sites of influenza virus neuraminidases might segregate independently in genetic recombination experiments (Kendal and Madelexy, 1969). Accordingly, the Michaelis constants of $X-7$ (FI) and $A_{2} /$ Singapore/57 virus neuraminidases were determined, using sialolactose substrate. $A_{0} / B E L / 35$ virus was also tested, as a representative of the $A_{0}$ /antigenic-type neuraminidases (PaNIKER, 1968). As shown in Table 3, the kinetic evidence provides further support for the proposed derivation of X-7 ( $\mathrm{Fl}$ ) neuraminidase. The $\mathrm{Km}$ of this viral enzyme was very similar to that of $A_{2} /$ Singapore/57, and quite different to the present value determined for $A_{0} / B E L / 35$, and the previously reported values for $A_{0} / P R 8 / 34, A_{0} / M E L / 35$, and $A_{0} / N W S / 39$ (Kkndal and MadeLEY, 1969).

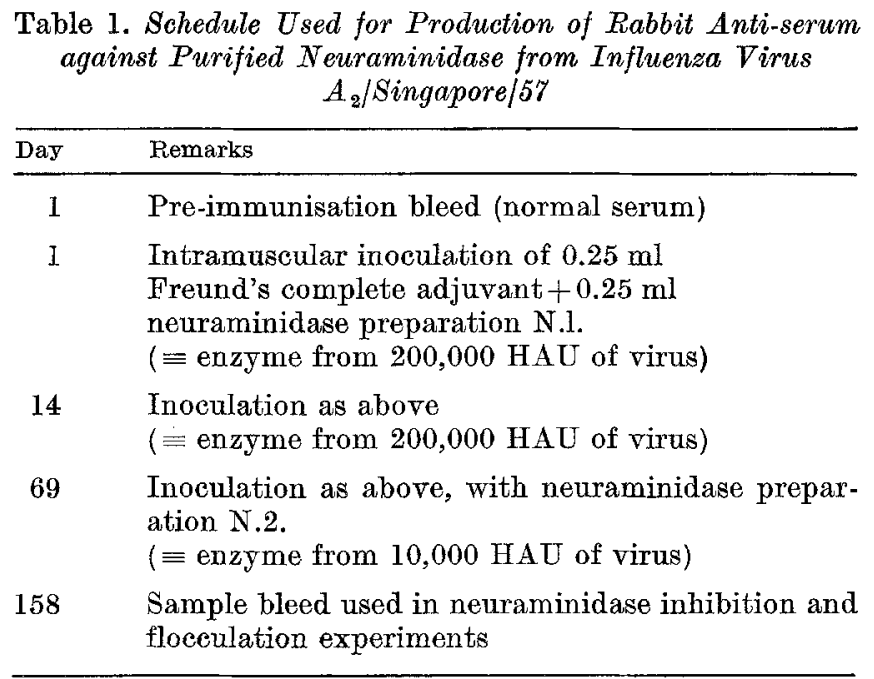

(days $8,14,17,21,29$ and 78 other sample bleeds)

\subsection{Flocculation of Influenza Virus by Antibodies Specific for Neuraminidase}

Initially, $A_{2} /$ Singapore/57 virus was used in these tests, and it was found that this virus could be flocculated by serum prepared against whole virus, and by serum prepared against isolated neuraminidase (Table 2). In repeated experiments using different preparations of $A_{2} /$ Singapore/57 virus, the floceulating titre of the 'anti-neuraminidase' serum was consistently about 2-fold less than that of the anti-whole virus serum. Although the anti-neuraminidase serum was obtained in response to purified neuraminidase antigen, the HI activity of this serum indicated that some antibodies directed against the viral haemagglutinin might also have been present. As varying degrees of inhibition of haemagglutination by different virus recombinants can apparently be produced by anti-neuraminidase antibodies (KILBOURNe, 1968), it is quite possible that the HI activity observed in the present experiment was the result only of steric hindrance by anti-neuraminidase antibodies. However, to confirm that flocculation of influenza virus particles could be induced by antibodies specific for neuraminidase, the X-7 (F1) 
virus was used, since none of the immune sera had any detectable haemagglutinating activity against this recombinant virus. As seen from Table 2, macroscopic aggregates of X-7 (F1) virus formed on mixing with these immune sera.

\subsection{Electron Microscopic Examination of Virus Floccules}

To verify that the aggregated material seen in the flocculation tests contained virus particles, and not just serum deposits, floccules were examined by negative staining technique in the electron microscope. Shown in Fig. 1 is the appearance

Table 2. Immunologic Reactions of $\bar{X}-7$ (F1) and $A_{2} /$ Singapore/57 Viruses with Rabbit Anti-sera

\begin{tabular}{lccccccc}
\hline Serum prepared against & \multicolumn{3}{l}{ Serum titres $^{1}$} \\
\cline { 2 - 7 } & $\begin{array}{l}\text { Anti- } \\
\text { neuraminidase }\end{array}$ & \multicolumn{2}{c}{$\begin{array}{l}\text { Anti- } \\
\text { baemagglutinin }\end{array}$} & \multicolumn{2}{c}{ Flocculation } \\
\hline No antigen (normal serum) & $75^{2}$ & $(65)$ & $<5$ & $(<5)$ & 8 & $(8)$ \\
$\begin{array}{l}\mathrm{A}_{2} / \text { Singapore/57 isolated neura- } \\
\text { minidase }\end{array}$ & 4,500 & $(9,000)$ & $<5$ & $(200)$ & 60 & $(80)$ \\
Whole virus $\mathrm{A}_{2} /$ Singapore/57 & 4,500 & $(6,750)$ & $<5$ & $(1,250)$ & 30 & $(120)$ \\
\hline
\end{tabular}

${ }^{1}$ For details of expression of serum titres, see "Methods".

2 lst Figure - reaction with X-7 (F1) virus.

2nd Figure, in parenthesis - reaction with $\mathrm{A}_{2} /$ Singapore/57 virus.

Table 3. Michaelis Constant ( $K m$ ) of Influenza Virus Neuraminidases for Sialo-lactose Substrate

\begin{tabular}{|c|c|c|}
\hline \multirow[t]{2}{*}{ Virus strain } & \multicolumn{2}{|c|}{$\mathrm{Km} \mathrm{M} / \mathrm{L} \times 10^{4}$} \\
\hline & Mean ${ }^{1}$ & Range \\
\hline $\mathrm{A}_{2} /$ Singapore/57 & 9.8 & $9.0-11$ \\
\hline $\mathrm{A}_{2} /$ Singapore $/ 57^{2}$ & 13.0 & $9.0-18$ \\
\hline$X-7(\mathrm{~F} 1)$ & 9.1 & $7.7-10$ \\
\hline $\mathrm{A}_{0} / \mathrm{BEL} / 35$ & 3.1 & $2.8-3.4$ \\
\hline $\mathrm{A}_{0} / \mathrm{NWS} / 39^{2}$ & 3.5 & $2.9-4.7$ \\
\hline
\end{tabular}

1 Mean $\mathrm{Km}$ values obtained from a minimum of 3 determinations.

${ }^{2}$ Previously determined values (KendaL and Madelex, 1969).

of the precipitate obtained when $\mathrm{A}_{2} /$ Singapore/57 virus was reacted with fully homologous anti-serum at a dilution of 1/20. Many aggregated virus particles were seen, no longer clearly showing the characteristic spikes seen in negatively stained control preparations. A number of the virions, particularly at the edge of the floccules, appeared to be surrounded by a 'halo' of material. This suggests that antibody molecules were binding around the tips of the spikes, and possibly not along their whole length.

When virus precipitated by specific anti-neuraminidase serum was examined, the spiky appearance of control virions was still seen quite clearly. Little dif- 
ference was observed between particles of $A_{2} /$ Singapore/57 or X-7 (F1) virus reacted with this serum (Fig. 2). In some areas around the particles material apparently binding to the spikes was present. Such areas were randomly distributed, and a diffuse 'halo' was not seen. Even when immune sera were reacted

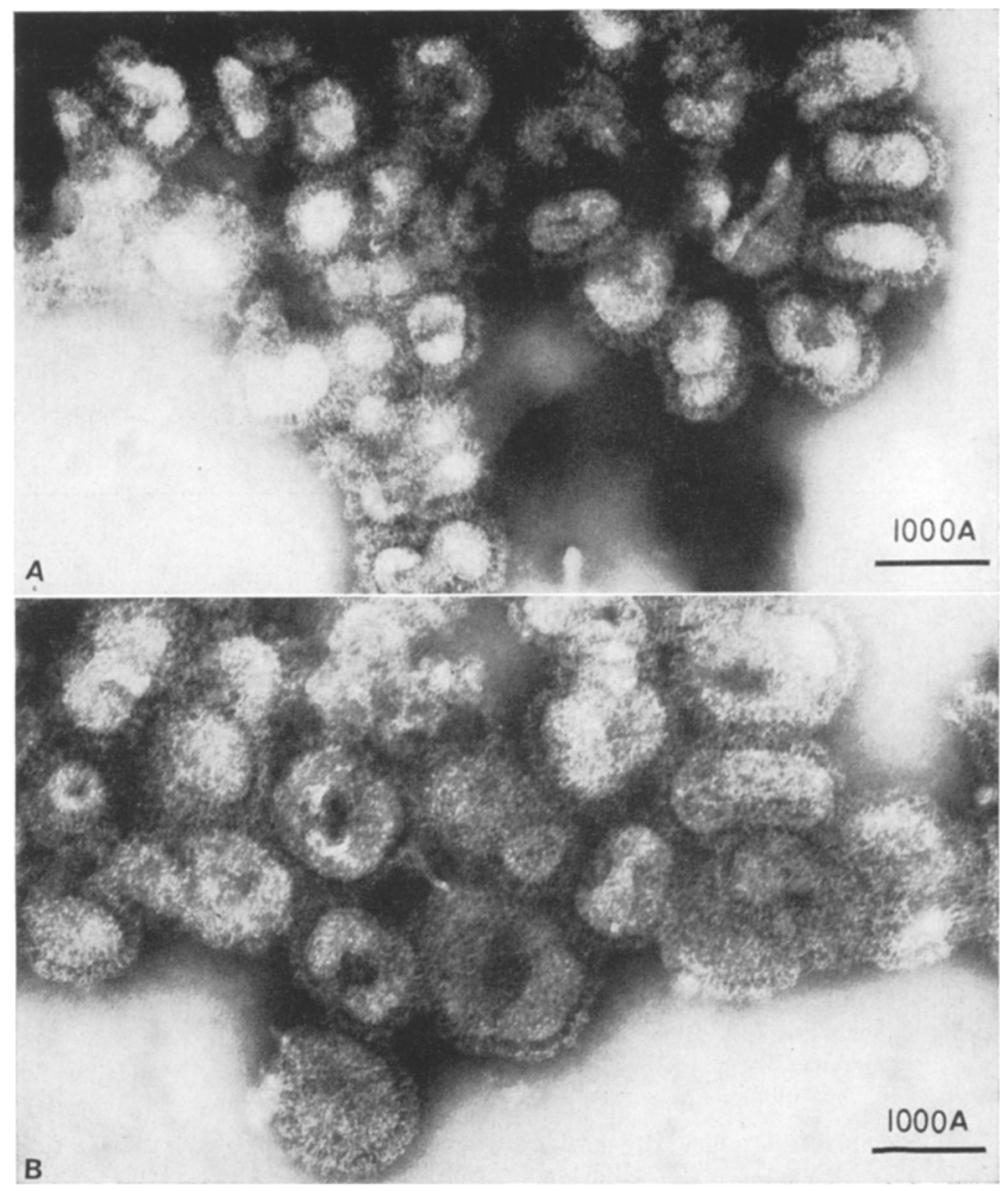

Fig. 1. A and B. Floccules of $A_{2} /$ Singapore/5i virus obtained with anti-A $2 /$ Singapore/57 serum (serum dilution, 1:20). Preparation negatively stained with P.T.A. The outermost ends of all the surface spilies are obscured by antibody

at a high dilution (1/400) so that no macroscopic virus precipitate formed, few single virus particles could be seen in the mixtures, most virions occurring in aggregates. Control virus preparations mixed with normal rabbit serum (1/20 dilution) contained predominantly individual virions, with occasional small groups. 


\section{Discussion}

The structural relationship of influenza virus haemagglutinin and neuraminidase components on the surface of the virions is still the subject for some speculation, and information on this subject is particularly required in connec-
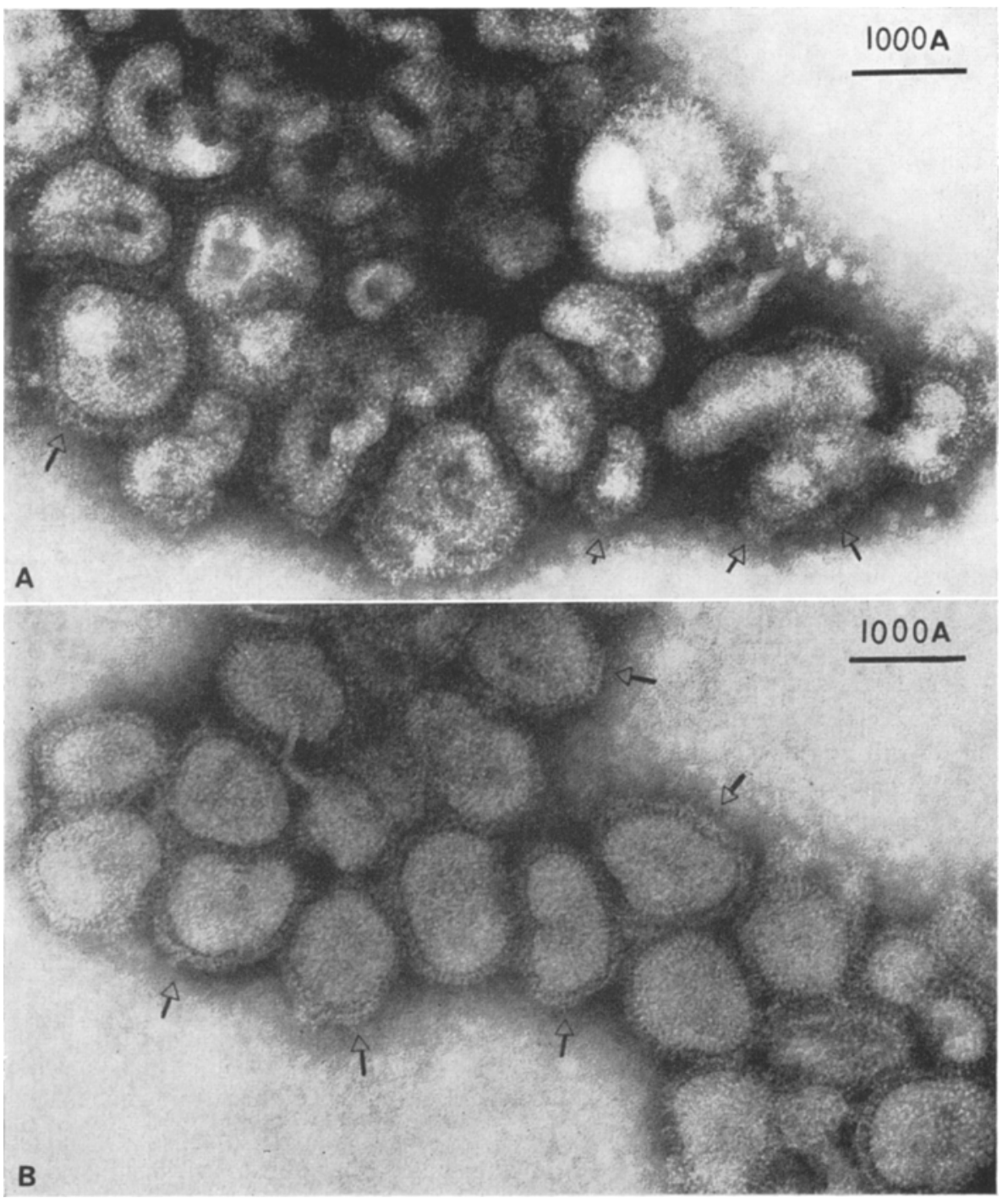

Fig. 2. Influenza virus floccules obtained with anti- $A_{2} /$ Singapore/57 neuraminidase serum (serum dilution, $1: 20$ ). A. $A_{2} /$ Singapore/ 57 virus floccules. B. $X-7$ (F 1) virus floccules Preparations negatively stained with P.T.A.

Large areas of the surface spikes appear unobscured, but the possible presence of antibody around the tips of the spikes may be seen localised in some places (arrowed)

tion with the possible interference by anti-neuraminidase antibody in haemagglutination inhibition tests used for typing viruses (see Schulman and KrLbodrne, 1969). 
Although it has been known for many years that influenza virus particles could be flocculated by specific immune sera (BELYAVIN, 1955), in retrospect the participation of viral haemagglutinin and neuraminidase in the aggregation reactions described could not be differentiated at that time. Subsequent experiments have shown that influenza viruses may be flocculated by non-antibody serum haemagglutination inhibitors (BIDDLE and STEVENSON, 1966), and the present experiments were designed to determine whether virus particles could be flocculated through their neuraminidase components.

For this conclusion to be drawn, it was important to demonstrate viral aggregation in a system where the effect of anti-haemagglutinin antibodies could be excluded. Therefore, X-7 (F1) virus was tested with sera obtained against neuraminidase from $A_{2} /$ Singapore/57 virus, since neuraminidase is the only surface antigen so far demonstrated to be common between these viruses (WEBsTer et al., 1968). Our finding of a strong similarity between the kinetic behaviour of the enzymes from these two viruses indicates that the resemblance between their neuraminidases extends to the molecular configuration at their active sites, and this is additional evidence for the proposed derivation of the $X-7$ (F 1 ) virus used in the aggregation reaction described here.

The present results therefore show conclusively that, under controlled experimental conditions, flocculation of influenza virus particles by specific antineuraminidase antibody does occur. We also found that even quite low antineuraminidase antibody concentrations produced microscopic aggregates of influenza virus, in agreement with the observations of SETo and Chava (1969).

Aggregation of virions can only occur if antibody can form bridges between one particle and another. Since the 'spikes' on each influenza virion are $100 \AA$ long, it will not be possible for flocculation to occur if viral antigen is located near the base of the spikes, and the rabbit antibody molecule Fab sites cannot stretch more than $120 \AA$ apart (VALENTINE and GreEN, 1967). Thus it would seem that neuraminidase antigens are not confined to the base of the spikes. This is further supported by the evidence in Plate 2, where antibody appears to be binding to the tips of the spikes, leaving the base visible. In addition, attachment of the anti-neuraminidase antibody seems to be localised to groups of spikes, rather than uniformly distributed over the surface. Such a possibility has been considered previously, in a discussion of how neuraminidase might be arranged on the surface of influenza virus particles so that both detergents and protease released enzymic structures of similar sedimentation coefficients (APostolov, FLEWETT and KENDAL, 1969).

The ability of anti-neuraminidase antibody to aggregate virions may be highly significant in interpreting the results of experiments designed to investigate the influence of such antibody on influenza virus replication. From the evidence that anti-neuraminidase antibody reduces the plaque size or yield of virus in influenza-infected cells (SETo and RotT, 1966; JAHTEL and KشBouRne, 1966; Webster and Laver, 1967; Kilbourne et al., 1968; Seto and Chang, 1969), it has previously been concluded that the enzymic function of neuraminidase in influenza replication is the release of matured virus from the cells (KILBourne et al., 1968). 
However, we would suggest that there is equally good reason to believe that the release of virus particles may be inhibited simply by anti-neuraminidase antibody aggregating virions to infected cells. Neuraminidase activity may be detected on the plasma membrane of influenza-infected cells, and is available for reaction with antibody (KendaL and Apostolov, 1969). Therefore, as the present experiments have shown that the neuraminidase present on influenza virions is available for aggregation reactions with antibody, it seems probable that antibody could bind virions to infected cells by attaching to neuraminidase molecules on each.

This hypothesis is in agreement with the electron microscopic observations of Steto and Chang (1969), and in addition explains the otherwise paradoxical behaviour of the recombinant influenza viruses $X-7$ (F1) and X-7 in plaque inhibition tests. For, if the release of virus particles from infected cells was dependant on the enzymic activity of neuraminidase, it would be anticipated that the release of $\mathrm{X}-7$ ( $\mathrm{Fl}$ l) virus would be less affected than $\mathrm{X}-7$ virus by antineuraminidase antibody, since X-7 (FI) virus contains twice the amount of neuraminidase present in X-7 (WEBSTER et al., 1968). In practice, the reverse has been found to be the case, for complete abolition of X-7 (FI) plaques is produced by anti-neuraminidase sera, whereas only the size, but not the number, of X-7 plaques is reduced under the same conditions (JAHIEL and KILBoUnne, 1966; Kilbourne et al., 1968).

This previously reported result is consistent with our present suggestion that the observed effects of anti-neuraminidase antibody in tissue culture and in ovo could be due to aggregation of virions to infected cells, since an increase in the number of neuraminidase sites on the virions (and by inference on the membrane of infected cells) would result in the formation of more antibody links, and correspondingly increase the stability of any virus-cell aggregates.

Experiments with mice have shown that the presence of circulating antineuraminidase antibodies correlates with a degree of protection against pulmonary virus infection (Scholman, KHakPour and Kilbourne, 1968). We have found a significant degree of protection associated with anti-neuraminidase antibodies in lethal neurotropic infection of ehickens by avian influenza viruses (ALLAN, MADELeY and KendaL, in preparation). These results suggest that anti-neuraminidase antibodies can limit the extent of influenzal infections in natural hosts. However, there is no indication whether the antibody effect observed was due to inhibition of neuraminidase enzymic activity or an aggregation phenomenon. Further experiments are now being planned to investigate the influence of antineuraminidase antibody on the replication of influenza viruses, in tissue culture and in natural hosts, under conditions where the possibility of virus-cell aggregation is prevented. In this way, it is hoped to obtain a better understanding of the enzymic function of neuraminidase.

A further observation from the present work was the indistinguishable appearance of floccules of $\mathrm{A}_{2} /$ Singapore/57 virus and $\mathrm{X}-7$ (F1) virus obtained with anti-neuraminidase serum (Fig. $2 \mathrm{~A}$ and $\mathrm{B}$ ), and it seems probable, therefore, that the haemagglutination inhibition activity of this serum against $A_{2} /$ Singapore/ 57 virus was due to anti-neuraminidase antibodies. A similar effect has been observed by Krlbourre (1968) with an inhibitor-sensitive variant of $A_{2} /$ Singapore/57. That the haemagglutinin of $\mathrm{X}-7$ (FI) virus was not inhibited by this 
anti-neuraminidase serum confirms that where the possibility exists of antineuraminidase antibodies interfering with viral haemagglutinin (and vice versa), each strain of influenza virus must be considered independently. It may also be concluded from the serological studies with $\mathrm{X}-7$ (F1) virus that the virus concentration used in the standard haemagglutination tests was too low to be flocculated by anti-neuraminidase sera. This question has also recently been discussed by WEBSTER (1969).

\section{Acknowledgements}

Photographic materials were partly obtained by a grant to C. R. Madeley from the Agricultural Research Council.

\section{References}

1. Ada, G. L., P. E. Lind, and W. G. Laver: An immunological study of avian, viral and bacterial neuraminidase based on specific inhibition of enzyme by antibody. J. gen. Microbiol. 32, 225 (1963).

2. Apostolov, K., T. H. Flewet, and A. P. Kendal: In: The Biology of Large RNA Viruses. (In press), Academic Press, 1970.

3. Belyavin, G.: The direct floceulation of influenza virus. Lancet $\mathbf{i}, 698$ (1955).

4. Bidder, F.: The action of protease on influenza $A_{2}$ virus. J. gen. Virol. 2, 19 (1968).

5. Bipdet, F., and K. F. Shortridge: Immunological eross-reactions of influenza virus inhibitors. Brit. J. exp. Path. 48, 285 (1967).

6. Biddle, F., and J. P. Stevenson: Floceulation of influenza viruses by horse serum inhibitor. Nature (Lond.) 209, 1223 (1966).

7. JAHIEL, R. I., and E. D. KILbourne: Reduction in plaque size and reduction in plaque number as differing indices of influenza virus-antibody reactions. J. Bact. 92, $1521(1966)$.

8. Kendal, A. P., and K. Apostolov: The production of neuraminidase in cells infected with influenza virus. Nature (Lond.) 226, 167 (1970).

9. Kendal, A. P., and C. R. Madeley: A comparative study of influenza virus neuraminidases, using automated techniques. Biochim. biophys. Acta (Amst.) 185, $163(1969)$.

10. Kendal, A. P., K. Apostolov, and G. Belyavin: The effect of protease treatment on the morphology of influenza A, B and C viruses. J. gen. Virol. 5, 141 (1969).

11. Kendal, A. P., F. Biddle, and G. Belyavin: Influenza virus neuraminidase and the viral surface. Biochim. biophys. Acta (Amst.) 165, 419 (1968).

12. Kilbourne, E. D.: Recombination of influenza A viruses of human and animal origin. Science 160, 74 (1968).

13. Kilbourne, E. D., and J. C. Schulman : The induction of broadened (multitypic) immunity with doubly antigenic influenza virus recombinants. Trans. Ass. Amer. Phyens. 88, 323 (1965).

14. Kilbourne, E. D., W. G. Laver, J. L. Schulman, and R. G. Webster: Antiviral activity of antiserum specific for an influenza virus neuraminidase. J. Virol. 2, 281 (1968).

15. Kilbourne, E. D., F. S. Lief, J. L. Schulman, R. I. Jahiel, and W. G. Laver: Antigenic hybrids of influenza viruses and their implications: In Perspect. Virol. 5, 87 (1967). M. Pollard (ed.), New York: Academic Press.

16. Laver, W. G., and E. D. Kilbourne: Identification in a recombinant influenza virus of structural proteins derived from both parents. Virology 30, 493 (1966).

17. Lennette, E. H., and Nathalie J. Schmidt: In: Diagnostic procedures for viral and rickettsial diseases. Amer. publ. Hlth Ass., 3rd. Ed., p. 465 (1964).

18. PANIKER, C. K. J.: Serological relationships between the neuraminidases of influenza viruses. J. gen. Virol. 2, 385 (1968). 
19. Rafelson, M. E., M. Schneir, and V. W. Wilson: Studies on the neuraminidase of influenza virus. II. Additional properties of the enzymes from the Asian and PR 8 strains. Arch. Biochem. Biophys. 103, 424 (1963).

20. Scholtissek, C., and R. Rotx: Behaviour of virus-specific activities in tissue cultures infected with myxoviruses after chemical changes of the viral ribonucleic acid. Virology 22, 169 (1964).

21. Scholtissek, C., H. Becht, and R. Drzeniek: Biochemical studies on the cytopathic effect of influenza viruses. J. gen. Virol. 1, 219 (1967).

22. Schulman, J. L., and E. D. Kilbourne: Independent variation in nature of hemagglutinin and neuraminidase antigens of influenza virus: Distinctiveness of hemagglutinin antigen of Hongkong/68 virus. Proc. nat. Acad. Sci. (Wash.) 63, 326 (1969).

23. Schulman, J. L., M. Khakpour, and E. D. Kilbourne: Protective effects of specific immunity to viral neuraminidase on influenza virus infection of mice. $J$. Virol. 2, 778 (1968).

24. Seto, J. T., and Flora S. Chang: Functional significance of sialidase during influenza virus multiplication: an electron microscope study. J. Virol. 4, 58 (1969).

25. Seto, J. T., K. OKUDA, and Y. Hoкama: Role of sialidase in the initial phase of infection with influenza virus. Nature (Lond.) 213, 188 (1967).

26. Seto, J. T., and R. Rotт: Functional significance of sialidase during influenza virus multiplication. Virology 30, 731 (1966).

27. VALEnTine, R. C., and N. M. GREEN : Electron microscopy of an antibody-hapten complex. J. molec. Biol. 27, 615 (1967).

28. Webster, R. G.: In: The Biology of Large RNA Viruses. (In press), Academic Press, 1970.

29. Webster, R. G., and W. G. LaVer : Preparation and properties of antibody directed specifically against the neuraminidase of influenza virus. J. Immunol. 99, 49 (1967).

30. Webster, R. G., W. G. Laver, and E. D. Kilbourne: Reactions of antibodies with surface antigens of influenza virus. J. gen. Virol. 3, 315 (1968).

Authors' address: Dr. A. P. Kendal, School of Public Health, University of Michigan, Ann Arbor, MI 48104, U.S.A. 